Malaysian Journal of Social Sciences and Humanities (MJSSH)

Volume 4, Issue 8, December 2019

e-ISSN : 2504-8562

Journal home page:

www.msocialsciences.com

\title{
Elemen Meneroka Bukti dalam Pembelajaran Sejarah Menggunakan Sumber Dokumen Teks
}

\author{
Siti Kisni Kisson', Christina Peter Ligadu1 \\ 1Universiti Malaysia Sabah (UMS) \\ Correspondence: Siti Kisni Kisson (ctniesk@gmail.com)
}

\begin{abstract}
Abstrak
Pembelajaran Sejarah dengan sumber dokumen teks di sekolah menengah atas telah dikaji. Tiga sumber dokumen teks dengan tajuk, "Perjuangan Mat Salleh menentang pendudukan British di Sabah", dianalisis menggunakan Model Pemikiran Sejarah. Kajian ini menggunakan pendekatan kualitatif dengan reka bentuk kajian kes kolektif. Empat belas pelajar dari 2 buah sekolah menengah kebangsaan harian di Sabah menjadi sampel kajian. Kaedah pengumpulan data kualitatif adalah melalui kaedah pemerhatian, temu bual kumpulan berfokus dan analisis dokumen. Didapati semua pelajar dapat membina Kemahiran Pemikiran Sejarah (KPS) dengan elemen meneroka bukti. Analisis data menunjukkan pelajar-pelajar membina elemen meneroka bukti dengan; mengemukakan pelbagai pendapat tentang penulis dokumen teks berdasarkan bukti, meneroka kebenaran bukti sejarah seperti sejarawan, mengenalpasti lokasi dan tempat perjuangan pemimpin tempatan, serta mempelajari peristiwa sejarah tempatan dengan pengesahan bukti sejarah.
\end{abstract}

Kata kunci: pembelajaran sejarah, sumber dokumen teks, kemahiran pemikiran sejarah, elemen meneroka bukti

\section{Element Exploring the Evidence in Learning of History Using a Text Documents Source}

\begin{abstract}
This study investigated the use of text documents source in learning of History in high school. Three sources of text documents related to the events of Mat Salleh's struggle against British occupation in Sabah, were studied using Historical Thinking Model. Qualitative approach were used with the design of a collective case study. Observation, focus group interviews and document analysis were carried out to collect the data needed. Fourteen students from two national secondary schools in Sabah were selected using purposive sampling. It is found that all students are able to develop Historical Thinking Skills (HTS) with the elements of exploring the evidence. The findings showed elements of exploring the evidence with; various opinions on the author of text documents sources, explore historical facts such as historians, identify locations of local leaders' struggles, and learning historical events with historical proofs.
\end{abstract}

Keywords: learning history, text documents source, historical thinking skills, element exploreing the evidence 


\section{Pengenalan}

Kajian ini dijalankan untuk meneroka penggunaan sumber dokumen teks dalam pembelajaran Sejarah di sekolah menengah yang melibatkan pelajar-pelajar Tingkatan Empat dari dua buah sekolah menengah harian di Sabah. Dalam kajian ini, tiga sumber dokumen teks yang berkaitan dengan peristiwa perjuangan Mat Salleh menentang pendudukan British di Sabah, telah digunakan dalam pengajaran dan pembelajaran (PdP) di bilik darjah. Sehubungan itu, sumber dokumen teks pertama (dokumen laporan) berupa laporan pegawai British dalam sebuah majalah terbitan tahun 1898 oleh Arkib Negeri Sabah telah digunakan. Sumber dokumen teks yang kedua (dokumen surat) berupa buku penulisan peristiwa perjuangan Mat Salleh yang memaparkan dua pucuk surat Mat Salleh kepada seorang pegawai British pada tahun 1898. Sumber dokumen teks ketiga (dokumen buku) merupakan petikan penulisan dalam sebuah buku tentang sejarah perjuangan Mat Salleh. Dokumen surat dan dokumen buku diperolehi dari Perpustakaan Negeri Sabah. Ketiga-tiga sumber dokumen teks ini digunakan dalam PdP di bilik darjah sebagai sumber maklumat utama mempelajari sejarah. Untuk meneroka penggunaan sumber dokumen teks, model pemikiran sejarah oleh Wineburg (2010) dan soalan-soalan yang telah diketengahkan oleh Reisman (2012) telah diintegrasikan bagi memberikan panduan dan bimbingan kepada pelajar-pelajar dalam strategi pembacaan dokumen teks sejarah.

\section{Kajian Literatur}

Penggunaan sumber sejarah melihat kepada tindakan seseorang ahli sejarah membuktikan kebenaran sesuatu peristiwa yang diaplikasikan di dalam bilik darjah. Dalam kajian pensejarahan, maklumat yang ditemui dari sumber sejarah akan dinilai, dipersoalkan dan disiasat sejauhmana kebenarannya (Zajda, Henderson dan Whitehouse, 2017). Proses tersebut memerlukan seseorang mengutarakan sebanyak mungkin pertanyaan dan mempersoalkan maklumat yang ditemui dengan kemahiran menyiasat, menyoal, menaakul dan mentafsir sesuatu peristiwa atau tokoh sejarah (De la Paz et al. 2016). Setiap satunya diselidik, diteroka dan dianalisis kandungannya untuk mencari persamaan dan perbezaan dengan sumber-sumber yang lain (Wineburg, Martin dan Monte-Sano, 2014). Hal yang demikian, sumber dokumen teks menjadi pilihan penyelidik untuk diteroka dan difahami penggunaannya dalam pembelajaran Sejarah.

Merujuk pada kajian lepas menunjukkan penekanan kepada pemikiran sejarah dalam kalangan pelajar (Levisohn, 2015). Turut dicadangkan agar pelajar-pelajar menjadi penyiasat sejarah dengan mengemukakan soalan, memilih sumber untuk mendapatkan maklumat dan peluang menyampaikan penemuan pelajar-pelajar ditekankan (Mohamad Johdi, Abdul Razaq dan Ahmad Rafaai, 2009). Hal ini dapat merangsang pemikiran pelajar, dengan proses mencari bukti, membuat pertimbangan dan rasionalisasi, interpretasi dan imaginasi (Lee, 2012).

Hal yang demikian, pemikiran bersejarah secara khususnya dikenali sebagai kemahiran pemikiran sejarah (KPS), turut menjadi teras dalam mata pelajaran Sejarah. Penerapan KPS dalam pendidikan Sejarah didapati mampu meningkatkan motivasi intrinsik dalam kalangan pelajar (Kaviza, Rahim dan Bukhari, 2018), menarik minat pelajar terhadap Sejarah dan mampu meletakkan pelajar pada kedudukan ciri-ciri seorang ahli sejarah (Zahara dan Nik Azleena, 2007; Cowgill II dan Waring, 2017). Justeru, pembinaan elemen meneroka bukti dalam KPS turut menjadi tumpuan dalam kajian ini.

Hal yang demikian, kajian ini mengintegrasikan model pemikiran sejarah (Wineburg, 2010). yang melibatkan proses analisis sumber (sourcing), kontekstualisasi (contextualization), engesahan (corroboration) dan pembacaan mendalam (close reading). Bagi tujuan membimbing pelajar-pelajar menganalisis dan membuat pentafsiran terhadap semua maklumat dokumen teks, soalan-soalan yang jelas perlu dikemukakan. Untuk kajian ini, turut diintegrasi ialah soalan-soalan sebagai bimbingan dan panduan kepada pelajar-pelajar (Reisman, 2012) untuk mengaplikasikan proses; analisis sumber, kontekstualisasi, pembacaan mendalam dan pengesahan. 


\section{Konsep Kemahiran Pemikiran Sejarah}

Pemikiran sejarah ditakrifkan sebagai penggunaan sumber sejarah yang terdiri daripada pelbagai artifak dan dokumen. Polman (2006) telah mentakrifkan pemikiran sejarah sebagai proses siasatan sejarah yang melibatkan proses menganalisis, mentafsir; serta membuat kesimpulan munasabah berdasarkan bukti sumber sejarah. Pemikiran sejarah turut ditakrifkan sebagai penilaian terhadap pelbagai sumber untuk menyelidiki kerumitan dan nuansa masa lalu (Burton, Pellegrino dan Gallagher, 2015).

Selanjutnya, memberikan peluang kepada para pelajar melibatkan diri dengan KPS membolehkan mereka menghubungkait fakta sejarah, menganalisis, mentafsir, mengkategorikan sumber sejarah, boleh membuat penilaian etika, berempati serta boleh memahami rentetan peristiwa sejarah (Shakila dan Nor Hashimah, 2016). Dalam erti kata lain, pendedahan awal penggunaan sumber sejarah memberikan peluang kepada pelajar-pelajar mempelajari peristiwa sejarah secara lebih mendalam dengan menghayati sejarah (Mohd Samsudin dan Shahizan, 2012). Keseluruhannya, pemikiran sejarah dikaitkan dengan sumber sejarah yang memerlukan pelajar-pelajar menganalisis sumber sejarah seperti seorang sejarawan.

Sehubungan itu, elemen meneroka bukti melibatkan kemahiran mengenalpasti sumber pertama dan kedua, serta membuat perbandingan antara kedua-dua sumber tersebut. Perkara ini dapat merangsang pemikiran sejarah seseorang pelajar, disamping memahami masalah sejarah dan sifatnya yang interpretatif (Kementerian Pendidikan Malaysia, 2003). Dalam pada itu, pengetahuan pelajar-pelajar tentang meneroka bukti, membolehkan mereka menganalisis sumber dan merekod hasil analisis (Kementerian Pendidikan Malaysia, 2015). Meneroka bukti turut memberikan peluang kepada pelajar merujuk pelbagai sumber yang berkaitan untuk mencari kebenaran, mengesahkan dan mendapatkan jawapan kepada pelbagai soalan. Dalam hal ini, penggunaan buku teks sahaja tidak cukup untuk membenarkan pelajar memperoleh kemahiran meneroka bukti (Rosy Talin, 2015). Sehubungan itu, pelajar perlu diajar menjadi penyelidik sejarah (Mohd Mahzan et al. 2016).

\section{Tujuan dan Objektif Kajian}

Kajian ini bertujuan untuk meneroka penggunaan sumber dokumen teks dalam pembelajaran mata pelajaran Sejarah di sekolah menengah. Objektif kajian ini adalah untuk meneroka bagaimana penggunaan sumber dokumen teks dapat membantu pembinaan elemen meneroka bukti dalam kalangan pelajar di dua buah sekolah menengah harian di Sabah.

\section{Metod Kajian}

Untuk kajian ini, pendekatan kualitatif dipilih kerana ia lebih menekankan konteks sosial bagi membolehkan informan berkongsi pandangan, pengalaman dan pemahaman mereka secara mendalam (Creswell, 2014). Selain itu, pendekatan kualitatif dianggap sesuai kerana kajian ini melibatkan interaksi manusia yang memerlukan penyelidik untuk cuba mentafsir atau memahami amalan manusia secara semulajadi (Mertens, 2005). Untuk kajian ini, penyelidik menekankan pembinaan makna, penerangan terperinci tentang pemikiran bersejarah dan pengalaman dalam penggunaan sumber dokumen teks.

Tumpuan kepada bagaimana informan memahami dan mempelajari peristiwa sejarah dengan penggunaan sumber dokumen teks daripada perspektif mereka sendiri, membawa kepada penggunaan kajian kes (Yin, 2014). Penerangan yang kaya tentang subjek daripada peserta kajian adalah penting (Merriam, 2015). Kes kajian melibatkan 14 informan pelajar yang terlibat dalam sesi PdP Sejarah dengan menggunakan sumber dokumen teks. Dalam kajian ini, penyelidik menggunakan kaedah sampel bertujuan (purposive sampling).

Kajian ini melibatkan proses kutipan data yang terperinci dan mendalam, dari sumber-sumber pemerhatian, temu bual dan analisis dokumen. Strategi menganalisis data merujuk kepada tiga 
peringkat: peringkat satu (manual); peringkat dua (koding); dan peringkat tiga (tafsiran data) (Corbin, Strauss, dan Strauss, 2014). Penyelidik menjalankan pemerolehan data daripada teknik temu bual kumpulan berfokus, secara tidak berstruktur. Akhirnya, analisis dokumen terdiri daripada jurnal pelajar dan hasil kerja bertulis pelajar.

\section{Dapatan Kajian}

\section{Pelbagai Pendapat Tentang Penulis Dokumen Teks berdasarkan Bukti}

Para pelajar bertindak untuk meneroka bukti yang ditulis oleh tiga penulis yang berbeza untuk dokumen laporan, dokumen surat dan dokumen buku. Seramai 10 daripada 14 pelajar memberikan pendapat bahawa mereka mengetahui siapa penulis sumber dokumen teks dengan tepat. Pelajar-pelajar mencatatkan bahawa dokumen laporan telah ditulis oleh "penulis yang terlibat pada masa itu" (ADK2). Seorang informan pelajar yang bernama Carl menerangkan bahawa mereka telah meneroka peristiwa Sejarah berdasarkan “... surat daripada Mat Salleh kepada KBBU ...” Avil mengesyaki bahawa pengintip ialah orang yang bertanggungjawab mencetuskan serangan British terhadap Mat Salleh. Menurut Avil, “... surat ini ditulis oleh seorang pengintip dari British yang berpura-pura berpihak kepada Mat salleh.”

\section{Meneroka Kebenaran Bukti Sejarah Seperti Sejarawan}

Proses menganalisis membolehkan para pelajar memahami bahawa penggunaan dokumen teks membolehkan mereka meneroka bukti. Separuh daripada 14 pelajar ini menyatakan bahawa tugasan yang mereka lakukan dalam kajian ini adalah seperti tugasan seorang sejarawan. Proses mereka menggunakan sumber dokumen teks dikaitkan dengan tugas-tugas yang sama dilakukan oleh seorang ahli sejarawan. Sewi merupakan informan pelajar yang menyamakan tugasan ini dengan berkata, "seperti sejarawan buat kerja kajian." Setiap kali aktiviti perbincangan dijalankan, kelihatan dokumen teks menjadi rujukan utama. Mereka agak teliti membaca dan meneroka maklumat yang terdapat pada dokumen teks. Ketika rakan-rakan mereka memberikan pendapat, pelajar yang lain akan membuat rujukan daripada dokumen teks. Kin memberikan penjelasan bahawa "kemungkinan proses yang sama digunakan oleh penulis tempatan." Sid turut menerangkan bahawa mereka mempelajari peristiwa sejarah berdasarkan bukti.

\section{Mengenalpasti Lokasi dan Tempat Perjuangan Pemimpin Tempatan}

Proses kontekstualisasi membolehkan semua 14 pelajar menerokai maklumat daripada sumber dokumen teks untuk mengenalpasti tempat dan lokasi peristiwa perjuangan Mat Salleh. Para pelajar mampu menganalisis daerah yang ada hubungkait dengan perjuangan pemimpin tempatan. Agak mudah untuk menggalakkan para pelajar memberikan penjelasan tentang lokasi dan tempat perjuangan Mat Salleh. Lokasi dan tempat yang dinyatakan tidak asing kepada mereka. Mereka mengetahui di mana terletaknya kedudukan setiap lokasi dan tempat tersebut, memandangkan lokasi-lokasi tersebut terletak di persekitaran negeri tempat tinggal mereka. Ketika menjawab soalan yang dikemukakan oleh guru tentang lokasi perjuangan Mat Salleh, mereka berebut-rebut mengangkat tangan ingin menjawab. Seorang informan pelajar yang lain bernama $\mathrm{Feb}$, boleh mengenalpasti lokasi perjuangan Mat Salleh; "menurut sumber, lokasi-lokasi yang berkaitan dengan penentangan Mat Salleh adalah di Pulau Jambongan, Tambunan, Sandakan dan Labuan. Saya tahu di mana." Ven menjelaskan dengan tersenyum bahawa dia berasa berpuas hati kerana "akhirnya, saya tahu banyak tempat perjuangan Mat Salleh seperti Sandakan, Pulau Gaya dan Tambunan." Dalam penulisan jurnal terdapat pelajar yang mencatatkan tentang "Mat Salleh merupakan pejuang di Sabah, Tambunan, dan Keningau. Semua dekat Sabah". Awang turut melaporkan bahawa "Mat Salleh menubuhkan kubu di Ranau dan menyerang Pulau Gaya. Masih ada sampai hari ini tempat itu”. 


\section{Mempelajari Peristiwa Sejarah Tempatan dengan Pengesahan Bukti Sejarah}

Dalam proses pengesahan, para pelajar kelihatan agak yakin dan bersemangat untuk meneruskan sesi pembelajaran. Mereka berupaya dan mampu menganalisis perbandingan maklumat daripada tiga dokumen teks. Pelajar-pelajar sendiri mengenalpasti dan menentukan maklumat yang dianggap penting dalam mempelajari peristiwa perjuangan Mat Salleh. Hampir semua pelajar menunjukkan kepastian bahawa peristiwa Mat Salleh adalah benar kerana terdapat "cerita yang sama ditulis dalam masa yang berbeza" daripada "beberapa sumber". Hasil tugasan berkumpulan dicatatkan tentang "...terdapatnya laporan British tentang penentangan Mat Salleh..." Catatan yang lain menunjukkan bahawa "Sumber British. Dalam majalah. Semua tahu betul". Avil menerangkan keinginan untuk meneroka bukti sejarah; "saya ingin mencari bahan rujukan yang lain tentang Mat Salleh. Seperti sumber daripada Jurnal UMS. Ditulis tahun 2001." Ven berpendapat bahawa "sumber dan pembuktian tu adalah untuk pengetahuan kita. Untuk mencari sumber sejarah atau apa-apa sahajalah tentang Mat Salleh."

\section{Perbincangan Dapatan Kajian}

Dapatan kajian menunjukkan pelajar-pelajar dapat membina elemen meneroka bukti sebagai elemen utama KPS. Elemen meneroka bukti ditunjukkan dalam proses analisis sumber, kontekstualisasi dan pengesahan. Dapatan kajian menunjukkan bahawa proses analisis sumber membolehkan para pelajar meneroka bukti daripada sumber dokumen teks. Mereka lebih yakin meneroka dan mentafsir latar belakang sumber dokumen teks. Para pelajar menghasilkan pelbagai pendapat tentang penulis dan tujuan sumber dokumen teks ditulis. Kepelbagaian pendapat ini memberikan pemahaman kepada pelajar-pelajar bahawa peristiwa sejarah dihasilkan daripada kepelbagaian pendapat sejarawan. Dapatan ini menepati kajian Goldman et al. (2016) tentang kewujudan kepelbagaian tafsiran dan pendapat penulis dalam dokumen sejarah, memberikan pemahaman bahawa sejarah adalah perbezaan tafsiran oleh sejarawan mengenai peristiwa sejarah yang sama.

Seterusnya, penggunaan sumber dokumen teks membolehkan para pelajar mengetahui bahawa sejarah dibina daripada kepelbagaian sumber sejarah. Mereka juga boleh memahami bahawa sokongan bukti perlu dalam membuktikan kebenaran sejarah. Para pelajar dapat meneroka bukti-bukti sejarah seperti seorang sejarawan kecil. Tugas para pelajar melibatkan penerokaan terhadap kebenaran bukti sejarah. Mereka mengetahui bahawa sumber dokumen teks memaparkan maklumat berbeza, memaparkan sudut pandangan, perspektif dan pemikiran penulis yang berbeza antara satu sama lain. Dapatan kajian ini selari dengan kajian Barnett (2014) yang berpendapat, pengalaman pelajar-pelajar berhadapan dengan sumber merupakan penglibatan secara langsung dengan pemikiran penulis sumber.

Dalam proses kontekstualisasi, para pelajar boleh mengesahkan lokasi dan tempat perjuangan Mat Salleh dengan membandingkan maklumat antara sumber dokumen teks. Peristiwa sejarah dapat disahkan dan dibuktikan benar dengan perbandingan maklumat dokumen laporan, dokumen surat dan dokumen buku. Dalam kajian ini, menggunakan sumber dokumen teks membuka peluang kepada pelajar-pelajar membuat penilaian terhadap sumber sejarah. Dapatan kajian ini menyamai kajian oleh Arlen, Clapp dan Craig (2015) tentang pelajar-pelajar yang boleh menganalisis dan membandingkan maklumat antara sumber dokumen teks.

Selanjutnya, kajian ini juga menunjukkan para pelajar dapat mengenalpasti persamaan dan perbezaan maklumat antara sumber dokumen teks. Dapatan kajian ini menyamai kajian Burton, Pellegrino dan Gallagher (2015) bahawa dalam usaha membuat penilaian terhadap sumber yang digunakan, pembaca boleh membezakan pelbagai jenis sumber dan boleh mengingati persamaan antara maklumat dan kandungan dokumen.

Keseluruhannya, penemuan kajian ini menunjukkan sumber dokumen teks boleh digunakan dalam pembelajaran Sejarah untuk para pelajar di sekolah menengah atas untuk membantu pembinaan elemen meneroka bukti dalam KPS. Elemen meneroka bukti dapat dikuasai oleh semua pelajar. Sehubungan itu, dapatan kajian ini diharapkan akan menambah pemahaman penggunaan sumber sejarah dalam 
Pendidikan Sejarah. Penglibatan pelajar-pelajar dalam menggunakan sumber dokumen teks memberikan mereka peluang membina KPS.

\section{Rujukan}

Arlen, S, Clapp, M, \& Craig, CL (2015). Producing tutorials with digital professionals: primary sources, pirates, and partners, Journal of Library Innovation, 6(1), 1-21.

Barnett, H (2014). Learning mathematics via primary historical sources: straight from the source's mouth', PRIMUS: Problems, Resources, and Issues in Mathematics Undergraduate Studies, 24(8), 722-736.

Burton, EP, Pellegrino, A \& Gallagher, M (2015). Humanizing the disciplines: historical thinking and students' understanding of the nature of science. The Georgia Social Studies Journal, 5(1), $54-$ 67.

Creswell, JW (2014). A concise introduction to mixed methods research. Thousand Oaks, CA, Sage Publications.

Cowgill II, DA \& Waring, SM (2017). Historical thinking: an evaluation of student and teacher to analyze sources', Journal of Social Studies Education Research, 8(1), 115-145.

De La Paz, S, Monte-Sano, C, Felton, M, Jackson, C, Piantedosi, KW \& Croninger, RA (2016). A historical writing apprenticeship for adolescents: integrating disciplinary learning with cognitive strategies. Reading Research Quarterly, 1-22.

Gall, MD, Gall, JP \& Borg, WR (2007). Educational research: an introduction, 8th edn, Boston, MA, Pearson.

Kaviza, MKM, Rahim, FA \& Bukhari, N., (2018). The relationship between readdiness of learning based historical sources towards intirinsic motivation. Jurnal Pendidikan Bitara 1(1), 52-63.

Kementerian Pendidikan Malaysia (2015). Kurikulum standard sekolah menengah, Sejarah, tingkatan 1', Putrajaya, Bahagian Pembangunan Kurikulum.

Kementerian Pendidikan Malaysia (2003). Sukatan pelajaran KBSM Sejarah (semakan)', Kuala Lumpur, Dewan Bahasa dan Pustaka.

Lee Bih Ni (2012). Applying technical-based analyzation to historical thinking skills: history teachers review', IRACST - International Journal of Advanced Computing, Engineering and Application (IJACEA), 1(3), 78-86.

Levisohn, JA (2015). Historical thinking - and its alleged unnaturalness', Educational Philosophy and Theory, 1-13.

Mertens, DM (2005). Research and evaluation in education and psychology, California, Sage Publications.

Merriam, SB (2015). Qualitative research: designing, implementing, and publishing a study' In Handbook of research on scholarly publishing and research methods, Hershey, Pa, IGI Global, 125-140.

Merriam, SB (2009). Qualitative research: a guide to design and implementation, San Francisco, CA, John Wiley \& Sons, Inc.

Mohamad Johdi Salleh, Abdul Razaq Ahmad \& Ahmad Rafaai Ayudin (2009). Penilaian kemajuan berasaskan sekolah kaedah kerja', Jurnal Pendidikan Malaysia, 34(2), 111 - 124.

Mohd Samsudin \& Shahizan Shaharuddin (2012). Pendidikan dan pengajaran mata pelajaran sejarah di sekolah di Malaysia', Jebat: Malaysian Journal of History, Politics and Strategic Studies, 39(2), 116-141.

Mohd Mahzan Awang, Abdul Razaq Ahmad, Noria Munirah Yakub \& Ahmad Ali Seman (2016). Historical thinking skills among pre-service teachers in Indonesia and Malaysia, Creative Education, 7, 62-76.

Polman, JL (2006). Mastery and appropriation as means to understand the interplay of history learning and identity trajectories, Journal of the Learning Sciences, 15, 221-59.

Reisman, A (2012). Reading like a historian: a document-based history curriculum intervention in urban high schools', Cognition and Instruction, 30(1), 86-112.

Rosy Talin (2015). Historical thinking skills-the forgotten skills?', In International Journal of Learning and Teaching, 7(1), 15-23. 
Shakila Che Dahalan \& Nor Hashimah Hashim (2016). The implementation Of historical thinking skills among teacher trainees in teaching learning process', 5th International Conference on Language, Education, and Innovation, Universiti Sains Malaysia, 28 May, pp. 211-218.

Wineburg, S, Martin, D \& Monte-Sano, C (2014). Reading like a historian, New York, Teachers College Press.

Wineburg, S (2010). Thinking like a historian. teaching with primary sources quarterly, 3(1), 2-5.

Yin, RL (2014). Case study research: design and methods, $5^{\text {th }}$ edition, Los Angeles, CA, Sage.

Zahara Aziz \& Nik Azleena Nik Ismail. (2007). Kemahiran pemikiran sejarah kepada para pelajar. Jurnal Pendidikan (UKM), 32, 119-137.

Zajda, J, Henderson, D \& Whitehouse, J (2017). The portrayal of John Curtin as Australia's wartime labor [JW2] prime minister in J Zajda, T Tsyrlina-Spady \& M Lovorn, (Eds.), Globalisation and historiography of national leaders: symbolic representations in school textbooks, Dordrecht, Netherlands, Springer. 